\title{
Improvement of Determination of Trace Amounts of Arsenic and Selenium in Slim Coffee Products by HG-ICP-OES
}

\author{
Maja Welna • Anna Szymczycha-Madeja $\cdot$ Pawel Pohl
}

Received: 26 July 2013 / Accepted: 20 August 2013 / Published online: 31 August 2013

(C) The Author(s) 2013. This article is published with open access at Springerlink.com

\begin{abstract}
A method for the determination of total inorganic arsenic and selenium in slim instant coffees using hydride generation inductively coupled plasma optical emission spectrometry (HG-ICP-OES) was proposed. Various sample preparation procedures, including the traditional total decomposition by the hot-plate or microwave heating in a $\mathrm{HNO}_{3} / \mathrm{H}_{2} \mathrm{O}_{2}$ mixture and alternative procedures based on the solubilisation in aqua regia or tetramethyl ammonium hydroxide (TMAH) and the dilution only with water or a low concentrated $\mathrm{HNO}_{3}$ solution were examined and compared. Corresponding As and Se hydrides were generated in the reaction of an acidified sample solution with the $\mathrm{NaBH}_{4}$ reductant in the presence of antifoam A. A small sample preparation with aqua regia in an ultrasonic bath followed by the pre-reduction with KI-ascorbic acid in the $\mathrm{HCl}$ medium for total As and the boiling with $\mathrm{HCl}$ for total Se were found to be optimal. The external calibration using standards treated and measured as the same as samples were applied for the analysis. Limits of detection (LODs) of 0.96 and $0.55 \mathrm{ng} \mathrm{ml}^{-1}$ were assessed for As and Se, respectively. The precision (as the relative standard deviation [RSD]) was within 1.6-7.1\%. The accuracy of the method was confirmed by the recovery test and the analysis of a standard reference material (non-fat milk powder, SRM 1459). The developed procedure was applied for the analysis of six commercial instant slim coffee products available in the Polish market and it was found that these products contain traces of As (0.114 $\left.0.247 \mu \mathrm{g} \mathrm{g}^{-1}\right)$ and Se $\left(0.089-0.137 \mu \mathrm{g} \mathrm{g}^{-1}\right)$.
\end{abstract}

Keywords Slim coffee - Sample preparation - Arsenic . Selenium $\cdot$ hydride generation $\cdot$ ICP-OES

M. Welna $(\bowtie) \cdot$ A. Szymczycha-Madeja $\cdot$ P. Pohl Chemistry Department, Analytical Chemistry Division, Wroclaw University of Technology, Wybrzeże Wyspiańskiego 27, 50-370 Wroclaw, Poland

e-mail: maja.welna@pwr.wroc.pl

\section{Introduction}

The coffee brew prepared from ground roasted coffee beans or soluble (instant) coffee belongs to a widely consumed nonalcoholic beverage worldwide. It is recognized as a rich source of elements, including essential as well as toxic, that the coffee plant may take up from a polluted soil, fertilizers or water and air contaminations. A concise review concerning the elemental analysis of coffee has been presented very recently by Pohl et al. (Pohl et al. 2013). Because of the ease of use and cleanliness of the preparation, soluble/instant coffee enjoys popularity (Vega-Carrillo et al. 2002; Oliveira et al. 2012) and today, an interest in the consumption of specific soluble coffees as slim coffees, can be observed. They are mixtures of instant coffee and various bioactive components, and therefore, the people, who wish to reduce their weight, prefer them. So far, however, no information on the elemental composition of such products has been reported.

Among various trace elements, Se is important and essential to the human health, while As is classified as one of the most toxic. Therefore, the assessment of their total contents in soluble coffee is of great importance, particularly because of its increasing popularity and a habitual consumption of this beverage. At present, the hydride generation (HG) technique coupled with the atomic spectrometry detection is a common method for the determination of traces of As and Se. The reduction of hydride-forming elements (e.g., $\mathrm{As}, \mathrm{Bi}, \mathrm{Sb}, \mathrm{Se}$ and $\mathrm{Sn}$ ) to volatile hydrides in the acid medium by sodium tetrahydroborate $\left(\mathrm{NaBH}_{4}\right)$ remarkably increases their detection performance as compared to conventional sample introduction by the pneumatic nebulisation (PN) (Pohl 2004).

Studies concerning Se and As in soluble coffee are rather scarcely documented than those devoted to other elements (Pohl et al. 2013). Accordingly, there have been only few reports on the concentration of aforementioned elements (Vega-Carrillo et al. 2002; Jose dos Santos and de Oliveira 
2001; Ribeiro et al. 2003; Asfaw and Wibetoe 2005). In general, the analysis of coffee on the content of As and $\mathrm{Se}$ are performed using inductively coupled plasma optical emission spectrometry (ICP-OES) with PN (Ribeiro et al. 2003) or HG (Jose dos Santos and de Oliveira 2001; Asfaw and Wibetoe 2005) after the previous sample total decomposition by means of the wet digestion in closed vessel microwave (MW)-assisted (Jose dos Santos and de Oliveira 2001; Asfaw and Wibetoe 2005) or open vessel (Ribeiro et al. 2003) systems in the presence of concentrated oxidative reagents, particularly mixtures of $\mathrm{HNO}_{3}+\mathrm{H}_{2} \mathrm{O}_{2}$. The direct analysis of solid coffee samples is also possible, carried out by the INNA method (Vega-Carrillo et al. 2002).

The traditional approach to the sample preparation of coffee prior to measurements of concentrations of various elements is the most tedious and time-consuming step of the whole analysis; it commonly requires the use of hazardous reagents and may lead to sample contamination or analyte losses. Alternative methodologies, involving partial or no previous decompositions, certainly could avoid or minimize all inconveniences related to sample digestion. Such procedures would be much simpler, faster and cheaper and could simultaneously provide accuracy and adequateness for routine analyses. Unfortunately, alternatives to acid-based procedures of the coffee sample preparation are rarely reported and utilised. To our best knowledge, there is no work on the evaluation of optimal conditions being suitable for the determination of total As and Se in soluble coffee products by the HG-ICP-OES hyphenated system with as little sample treatment as possible. So far, an alkaline solubilisation of instant coffee in tetramethyl ammonium hydroxide (TMAH) solution has been proposed by Ribeiro et al. (Ribeiro et al. 2003) for ICP-OES multi-element measurements, including Se. Asfaw and Wibetoe (Asfaw and Wibetoe 2005) have tested the dissolution in a $0.36 \mathrm{~mol}^{-1} \mathrm{HNO}_{3}$ solution and the solubilisation in aqua regia to determine hydride (Se) and non-hydride forming elements by ICP-OES using a dual-mode sample introduction system (MSIS) in various beverages (e.g., instant coffee). Alternative procedures using a slurry sampling (SS) technique based on the dispersion of soluble coffee powders in a mixture of diluted $\mathrm{HNO}_{3}(1-2 \%$, v/v) and Triton X$100(1-10 \%, \mathrm{v} / \mathrm{v})$ solutions have also been proposed (Anthemidis and Pliatsika 2005; Magalhaes et al. 1999), but with a special attention to the determination of $\mathrm{Al}, \mathrm{Ca}, \mathrm{Co}, \mathrm{Cr}$, $\mathrm{Cu}, \mathrm{Fe}, \mathrm{Mg}, \mathrm{Mn}, \mathrm{Ni}$ and $\mathrm{Zn}$ by graphite furnace atomic absorption spectrometry (GFAAS) or ICP-OES.

In this work we compare several different sample processes (traditional and alternative), and propose a simple procedure, i.e., with no previous complete digestion, which is accurate and precise for the determination of total As and Se within a low concentration range in soluble slim coffee products by HG-ICP-OES. The HG reaction from As(III), As(V), Se(IV) and $\mathrm{Se}(\mathrm{VI})$ was also optimised, taking into account its application in measurements of As and Se in real samples. The selected procedure was applied for the analysis of six different instant slim coffees commercially available in Poland. To our best knowledge, this marks the first report on the analysis of such coffee products, aimed at the evaluation of traces of As and Se with the undemanding sample treatment.

\section{Experimental}

\section{Samples and Reagents}

Six instant slim coffee products (numbered as SC1-SC6) available in the Polish market were analysed. A standard reference material used to test the accuracy was a non-fat milk powder (SRM 1459) from National Institute of Standards and Technology (NIST).

All chemicals were of analytical grade. Concentrated $\mathrm{HNO}_{3}$ (Merck, Darmstadt, Germany), $\mathrm{HCl}$ (POCh, Gliwice, Poland) and $\mathrm{H}_{2} \mathrm{O}_{2}$ (POCh) solutions and solid TMAH (Sigma-Aldrich, Germany) were used for the sample preparation. Aqua regia was prepared by mixing 3:1 (v/v) concentrated $\mathrm{HCl}$ and $\mathrm{HNO}_{3}$ solutions. Stock standard solutions $\left(1,000 \mu \mathrm{g} \mathrm{ml}^{-1}\right)$ of $\mathrm{As}(\mathrm{III}), \mathrm{As}(\mathrm{V}), \mathrm{Se}(\mathrm{IV})$ and $\mathrm{Se}(\mathrm{VI})$ were obtained from their salts, i.e., $\mathrm{Na}_{3} \mathrm{AsO}_{3}, \mathrm{NaHAsO}_{4} \cdot 7 \mathrm{H}_{2} \mathrm{O}$ (Sigma-Aldrich), $\mathrm{Na}_{2} \mathrm{SeO}_{3}$ and $\mathrm{Na}_{2} \mathrm{SeO}_{4}$ (POCh). Working standard solutions (up to $5.0 \mu \mathrm{g} \mathrm{ml}^{-1}$ for calibration curves and $0.25 \mu \mathrm{g} \mathrm{ml}^{-1}$ for optimization investigations) were prepared by appropriate stepwise dilutions of concentrated solutions. A $1.0 \%(\mathrm{~m} / \mathrm{v})$ reductant solution was made daily by dissolving an appropriate amount of powder $\mathrm{NaBH}_{4}$ (SigmaAldrich) in $0.1 \mathrm{~mol} \mathrm{l}^{-1} \mathrm{NaOH}$ (POCh) and filtering $(0.45 \mu \mathrm{m})$ before being used. A $30 \%$ aqueous emulsion of Anti foam A (Sigma-Aldrich) was used as the anti-foaming agent during the HG reaction. Solid KI, ascorbic acid and tiourea (POCh) were used as pre-reducing agents. A $10 \%(\mathrm{~m} / \mathrm{v}) \mathrm{KI}$ solution in $2.0 \%(\mathrm{~m} / \mathrm{v})$ ascorbic acid and $10 \%(\mathrm{~m} / \mathrm{v})$ tiourea were prepared by dissolving reagents in water. Deionised water $(18.3 \mathrm{M} \Omega \mathrm{cm})$ from an EASYpure system (Barnstead, Model D7033) was used in all experiments.

\section{Sample Preparation Methods}

Samples were prepared as described in the following subsections.

\section{Open Vessel Hot-Plate Heating Digestion (P1)}

Coffee samples $(0.5 \mathrm{~g})$ were placed into $150-\mathrm{ml}$ Pyrex beakers with $12 \mathrm{ml}$ of a concentrated $\mathrm{HNO}_{3}$ solution and left for the pre-digestion overnight. Then, sample solutions were hotplate heated $\left(85^{\circ} \mathrm{C}\right)$ until all fumes of nitrogen oxides were ceased. Next, $3 \mathrm{ml}$ of a $30 \%$ (v/v) $\mathrm{H}_{2} \mathrm{O}_{2}$ solution was added. Resulting sample solutions were heated again to reduce their 
volumes to about $2 \mathrm{ml}$, and then quantitatively transferred into $25-\mathrm{ml}$ volumetric flasks and made up to the volume with deionised water.

\section{Closed Vessel Microwave-Assisted Digestion (P2)}

About $0.5 \mathrm{~g}$ of coffee samples was subjected to MW heating at a maximum power of $600 \mathrm{~W}$ for $45 \mathrm{~min}$ using concentrated reagents, $\mathrm{HNO}_{3}+\mathrm{H}_{2} \mathrm{O}_{2}(6+1 \mathrm{ml})$. After cooling, residual solutions were quantitatively transferred into $25-\mathrm{ml}$ volumetric flasks and made up to the volume with deionised water.

Digests of samples from both procedures $(\mathrm{P} 1, \mathrm{P} 2)$ were clear and colourless solutions.

\section{Solubilisation in Aqua Regia (P3)}

About $0.5 \mathrm{~g}$ of coffee samples was weighed into $30-\mathrm{ml}$ polypropylene (PP) centrifuge tubes; then $2 \mathrm{ml}$ of aqua regia was added and left to react. Next, resulting yellow-orange slurries were sonicated in an ultrasonic bath for $15 \mathrm{~min}$, made up to $25 \mathrm{ml}$ with deionised water and finally centrifuged $(10 \mathrm{~min}$, $12,000 \mathrm{rpm})$. As a result, bright-yellow solutions were obtained.

\section{Solubilisation in TMAH (P4)}

About $0.5 \mathrm{~g}$ of coffee samples was weighed into PP tubes, then treated with $1.0 \mathrm{ml}$ of a $25 \%(\mathrm{~m} / \mathrm{v})$ TMAH aqueous solution and left to react. Next, tubes with brown slurries were shaken $\left(80{ }^{\circ} \mathrm{C}, 30 \mathrm{~min}\right.$ ), cooled, diluted to $25 \mathrm{ml}$ with deionised water and finally centrifuged (10 min, 12,000 rpm). Resulting sample solutions were bright-brown.

\section{Dissolution in $\mathrm{HNO}_{3}$ (P5) or Water (P6)}

About $1.0 \mathrm{~g}$ of coffee samples was weighed into PP tubes and dissolved in $10 \mathrm{ml}$ of a $2.0 \%(\mathrm{v} / \mathrm{v}) \mathrm{HNO}_{3}$ solution or water and then centrifuged (10 $\mathrm{min}, 12,000 \mathrm{rpm})$ to remove any solid particles. Dark-brown sample solutions were obtained.

All sample solutions were analysed in triplicate $(n=3)$. Coffee SC1 was selected and used for optimization studies. With each set of sample solutions, blanks were prepared to correct final results. To avoid differences between the composition of sample and standard solutions, working standard solutions of $\mathrm{As}(\mathrm{III}, \mathrm{V})$ and $\mathrm{Se}(\mathrm{IV}, \mathrm{VI})$ were also processed through all preparation procedures. The selected procedure providing the most reliable results was applied to prepare remaining slim coffees and analyse them for As and Se by HG-ICP-OES against the external calibration.
Pre-treatment for Total As and Se Determination by HG-ICP-OES

For total As and Se determination, any $\mathrm{As}(\mathrm{V})$ form present was pre-reduced to As(III) with $1.0 \% \mathrm{KI}$ (in $0.2 \%$ ascorbic acid) and $3.0 \mathrm{~mol} \mathrm{l}^{-1} \mathrm{HCl}$. Accordingly, an aliquot of $2.5 \mathrm{ml}$ of each sample solution was transferred to a $5-\mathrm{ml}$ volumetric flask; then $0.5 \mathrm{ml}$ of $10 \% \mathrm{KI}$ in $2.0 \%$ ascorbic acid and $1.25 \mathrm{ml}$ of concentrated $\mathrm{HCl}$ were added and left to react for about $30 \mathrm{~min}$. After this time, the sample solution was diluted to the volume with deionised water. For Se, any $\mathrm{Se}(\mathrm{VI})$ form present was pre-reduced to Se(IV) by heating with $6.0 \mathrm{~mol}^{-1}$ $\mathrm{HCl}$. Accordingly, an aliquot of $1.5 \mathrm{ml}$ of each sample solution was transferred to a $10-\mathrm{ml}$ tube and poured with $1.5 \mathrm{ml}$ of concentrated $\mathrm{HCl}$. The tube was stoppered and heated in a water bath at $90^{\circ} \mathrm{C}$ for $30 \mathrm{~min}$. Total As (as As(III) in the first sample aliquot) and total Se (as Se(IV) in the second sample aliquot) were then measured by HG-ICP-OES.

\section{Hydride Generation}

As and Se hydrides were generated in a continuous flow system with a gas-liquid phase separation system coupled to the ICP-OES spectrometer. The system consisted of a modified cyclonic spray chamber, a parallel pneumatic nebulizer (Burgener) and peristaltic pumps with delivery tubes (Welna et al. 2011). In the manifold applied, an acidified sample solution was mixed with the reductant solution in a Yjunction and then, the reaction mixture was introduced at the bottom of the chamber to a special reaction cavity. Hydrides and other gaseous co-products were swept by a carrier $\mathrm{Ar}$ stream, introduced through the nebulizer gas inlet, and transported into the plasma. The sample inlet of the nebulizer was clogged. Post-reaction wastes were drained with the aid of a peristaltic pump. For a better plasma stability, the level of liquid in the chamber was controlled and kept at a constant level. The same spray chamber and nebulizer were also used to nebulise the sample solution.

\section{Apparatus}

Measurements of total As and Se was performed using a Jobin Yvon (France) sequential ICP-OES instrument (JY 38S). Working parameters for the HG reaction and the ICP-OES detection are listed in Table 1. After the reaction mixture passed into the chamber, $30 \mathrm{~s}$ were necessary to achieve steady As and Se signals.

A Milestone (Italy) high-pressure MW digestion system (MLS-1200 MEGA), equipped with a rotor MDR 300/10, was used for the MW-assisted sample decomposition. An Elpin (Poland) thermostatic water bath shaker (type 357) and a JP Selecta (Spain) ultrasonic bath (UltrasonsH) were used for experiments with aqua regia and TMAH-based sample 
Table 1 HG-ICP-OES operating parameters

\begin{tabular}{|c|c|}
\hline Generator (MHz) & 40.68 \\
\hline Rf power (W) & 1000 \\
\hline Injector i.d. (mm) & 2.5 \\
\hline Observation zone & $12 \mathrm{~mm}$ above load coi \\
\hline \multirow[t]{3}{*}{ Ar flow rates $\left(1 \min ^{-1}\right)$} & Plasma gas: 13.0 \\
\hline & Sheath gas: 0.20 \\
\hline & Carrier gas: 0.25 \\
\hline $\begin{array}{l}\text { Solutions uptake }\left(\mathrm{ml} \mathrm{min}{ }^{-1}\right) \\
\quad \text { (acidified sample, reductant) }\end{array}$ & 1.0 \\
\hline Replicates & 3 \\
\hline \multirow[t]{2}{*}{ Wavelength (nm) } & As I 197.3 \\
\hline & Se I 196.1 \\
\hline \multicolumn{2}{|l|}{ Hydride generation optimum condition } \\
\hline $\begin{array}{l}\left.\mathrm{NaBH}_{4} \text { concentration (in } 0.1 \mathrm{~mol}^{-1} \mathrm{NaOH}\right) / \\
\%(\mathrm{~m} / \mathrm{v})\end{array}$ & 1.0 \\
\hline Sample acidity with $\mathrm{HCl}\left(\mathrm{mol} \mathrm{l}^{-1}\right)$ & $3.0(\mathrm{As})$ and $6.0(\mathrm{Se})$ \\
\hline $\mathrm{KI}$-ascorbic acid concentration, $\%(\mathrm{~m} / \mathrm{v})$ & $1.0-0.2$ \\
\hline
\end{tabular}

solubilisations. An MPW-350 centrifuge (MPW Med. Instruments, Poland) was used to separate liquid phases from solid particles.

\section{Results and Discussion}

\section{Preliminary Studies}

The effect of the oxidation state of As and Se for HG was firstly studied. Typical $\mathrm{HG}$ reaction conditions were used for this, i.e., $\mathrm{NaBH}_{4}$ and $\mathrm{HCl}$ concentrations were kept at $1.0 \%$ and $3.0 \mathrm{~mol} \mathrm{l}^{-1}$, respectively. Single standard solutions of $\mathrm{As}(\mathrm{III}, \mathrm{V})$ and $\mathrm{Se}(\mathrm{IV}, \mathrm{VI})$ were acidified with $\mathrm{HCl}$, and corresponding hydrides were generated by merging them with the $\mathrm{NaBH}_{4}$ solution. As could be expected, the $\mathrm{Se}(\mathrm{VI})$ form was not reduced and no signal from this element was recorded. Both $\mathrm{As}(\mathrm{III})$ and $\mathrm{As}(\mathrm{V})$ forms reacted with $\mathrm{NaBH}_{4}$, but with different efficiency and response - the signal originated from As $(\mathrm{V})$ was about $70 \%$ of that provided by As(III). In view of this, the pre-reduction was necessary prior to the determination of total As and $\mathrm{Se}$ in real samples. In addition, it was found that higher $\mathrm{NaBH}_{4}$ concentrations than $1.0 \%$ made the plasma unstable; therefore, $1.0 \% \mathrm{NaBH}_{4}$ was used in further studies.

Next, conditions for the quantitative pre-reduction of $\mathrm{As}(\mathrm{V})$ and $\mathrm{Se}(\mathrm{VI})$ into As(III) and Se(IV) were established. Three reagents were tested: solutions of concentrated $\mathrm{HCl}$, $1.0 \% \mathrm{KI}$ in $0.2 \%$ ascorbic acid (KI) and $1.0 \%$ tiourea (TU). Medium of $3 \mathrm{~mol} \mathrm{l}^{-1} \mathrm{HCl}$ was used for pre-reduction with $\mathrm{KI}$ and TU. $\mathrm{As}(\mathrm{III}), \mathrm{As}(\mathrm{V}), \mathrm{Se}(\mathrm{IV})$ and $\mathrm{Se}(\mathrm{VI})$ standard solutions were subjected to the analysis and signals of elements were measured. It was found that the $\mathrm{KI}-$ ascorbic acid mixture and tiourea provide an effective reduction of $\mathrm{As}(\mathrm{V})$ at ambient temperatures. Moreover, they enhance the As signal coming from $\mathrm{As}(\mathrm{III})$ by about $38 \%$ and $32 \%$ for $\mathrm{KI}$ and TU, respectively. The solution of $\mathrm{HCl}$ alone could not reduce $\mathrm{As}(\mathrm{V})$ to its (III) oxidation state. In contrast, for Se, only the boiling with $\mathrm{HCl}$ was established to be the most appropriate. The quantitative reduction of $\mathrm{Se}(\mathrm{VI})$ was achieved by heating with $6.0 \mathrm{~mol}{ }^{-1} \mathrm{HCl}$ at $90{ }^{\circ} \mathrm{C}$ for $30 \mathrm{~min}$. The use of KIascorbic acid led to no signal recorded for Se, likely to the reduction of $\mathrm{Se}(\mathrm{IV})$ and $\mathrm{Se}(\mathrm{VI})$ to the Se zero state (Uggerud and Lund 1995). In the presence of tiourea, $\mathrm{Se}(\mathrm{VI})$ was found to be partially reduced $(\sim 30 \%)$ to Se(IV), while the Se signal from $\mathrm{Se}(\mathrm{IV})$ was only $60 \%$ of that obtained after the $\mathrm{HCl}$ treatment.

Based on these results, $6.0 \mathrm{~mol}^{-1} \mathrm{HCl}$ (for Se) and both KI and TU (for As) were selected for the investigation.

Next, the performance of the HG reaction was verified for standards prepared and proceeded in the same way as real samples (procedures P1-P6 and pre-reductions). Standard solutions of $\mathrm{Se}(\mathrm{IV})$ in $6.0 \mathrm{~mol} \mathrm{l}^{-1} \mathrm{HCl}$ and of $\mathrm{As}(\mathrm{III})$ in $3.0 \mathrm{~mol} \mathrm{l}^{-1} \mathrm{HCl}$ were taken as references for Se and As, respectively. Effects of the standard solution composition on the efficiency of the As and Se hydride generation are detailed in Table 2.

Independently of the sample preparation procedure used, complete pre-reductions of $\mathrm{As}(\mathrm{V})$ and $\mathrm{Se}(\mathrm{VI})$ were obtained. It was established that in the case of Se, the treatment with TMAH (P4) results in a small increase (8-12\%) in its signal, while the use of the dissolution in water only (P6) was found to reduce the signal of this element by about $20 \%$. The use of aqua regia (P3), the dissolution in diluted $\mathrm{HNO}_{3}(\mathrm{P} 5)$ or the mineralization in different conditions $(\mathrm{P} 1, \mathrm{P} 2)$ does not change the signal of Se and provides sensitivities comparable to this recorded for the reference Se standard. Considering these results, it seems that various sample preparation methodologies for the total Se determination used here have a slight effect on the efficiency of selenium HG. An opposite effect was observed in the case of As. It was found that in the presence of $\mathrm{KI}$-ascrorbic acid, added to pre-reduce $\mathrm{As}(\mathrm{V})$, the reduction of the As signal by about $15 \%$ was observed for conditions used in mineralization procedures (P1,P2). For the remaining procedures (P3-P6), improvements of the As response were noticed (35-56\%), and this effect was more pronounced (51-56\% increase) when the treatment with aqua regia (P3) or TMAH (P4) was used. Taking into account the enhancement of the As signal from As(III) after adding KI $(38 \%)$ to the reference standard, it can be concluded that diluted $\mathrm{HNO}_{3}$ (P5) and water (P6) do not influence the As emission. Changes in the intensity of this element are likely due to the KI addition. For procedures $\mathrm{P} 3$ and $\mathrm{P} 4$, it seems that both aqua regia or TMAH used for sample preparation and KI 
Table 2 Ratio (R\%) of intensities of elements recorded for standards prepared and proceed as real samples (procedures P1-P6 and pre-reductions) to reference standards ${ }^{\mathrm{a}}$ (optimal conditions for HG-ICP-OES measurements of As and Se)

\begin{tabular}{|c|c|c|c|c|c|c|}
\hline \multirow{3}{*}{$\begin{array}{l}\text { Pre-reducing reagent } \\
\text { Element }\end{array}$} & \multicolumn{2}{|c|}{$6.0 \mathrm{~mol} \mathrm{l}^{-1} \mathrm{HCl}$} & \multicolumn{2}{|c|}{$\begin{array}{l}1.0 \% \mathrm{KI}-0.2 \% \text { ascorbic } \\
\text { acid (in } 3.0 \mathrm{~mol} 1^{-1} \mathrm{HCl} \text { ) }\end{array}$} & \multicolumn{2}{|c|}{$\begin{array}{l}1.0 \% \text { tiourea }(\mathrm{TU}) \\
\text { (in } 3.0 \mathrm{~mol} \mathrm{l}^{-1} \mathrm{HCl} \text { ) }\end{array}$} \\
\hline & \multicolumn{2}{|l|}{$\mathrm{Se}$} & \multicolumn{2}{|l|}{ As } & & \\
\hline & $\mathrm{Se}(\mathrm{IV})$ & $\mathrm{Se}(\mathrm{VI})^{\mathrm{b}}$ & $\mathrm{As}(\mathrm{III})$ & $\operatorname{As}(V)^{b}$ & As(III) & $\operatorname{As}(\mathrm{V})^{\mathrm{b}}$ \\
\hline \multicolumn{7}{|l|}{ Procedure $(\mathrm{P})$} \\
\hline Digestion in $\mathrm{HNO}_{3} / \mathrm{H}_{2} \mathrm{O}_{2}(\mathrm{P} 1, \mathrm{P} 2)$ & 97.9 & 105 & 81.8 & 86.4 & 65.3 & 60.8 \\
\hline Solubilisation in aqua regia $(\mathrm{P} 3)$ & 103 & 104 & 156 & 152 & 129 & 132 \\
\hline Solubilisation in TMAH (P4) & 112 & 108 & 155 & 151 & 134 & 129 \\
\hline Dissolution in $2 \% \mathrm{HNO}_{3}(\mathrm{P} 5)$ & 96.9 & 95.6 & 144 & 141 & 131 & 136 \\
\hline Dissolution in $\mathrm{H}_{2} \mathrm{O}$ (P6) & 77.6 & 80.0 & 138 & 135 & 133 & 134 \\
\hline
\end{tabular}

${ }^{a}$ Reference (optimal) condition: $\mathrm{Se}(\mathrm{IV})$ in $6.0 \mathrm{~mol}^{-1} \mathrm{HCl}(\mathrm{Se})$ and $\mathrm{As}(\mathrm{III})$ in $3.0 \mathrm{~mol}^{-1} \mathrm{HCl}$ (As)

${ }^{\mathrm{b}}$ As As(III) or Se(IV) after pre-reductions

may lead to an improvement of the As signal. If TU was used to pre-reduce $\mathrm{As}(\mathrm{V})$, the reduction of the As signal was also noticed under mineralization conditions (P1,P2); however, the effect was stronger $(\sim 35 \%)$ than that obtained when $\mathrm{KI}$ was employed. Similarly, for other procedures (P3-P6) the As response was increased, but in this case the effect of the reagent used for the sample preparation is rather negligible if one takes into account the As signal enhancement coming from addition of TU only (32\%) to the reference standard. Therefore, the KI-ascorbic acid mixture was selected finally as the pre-reducing reagent for the total As determination. Noteworthy, these investigations confirmed the necessity of the preparation of standard and sample solutions in the same experimental conditions in order to obtain reliable results. It is especially important in the case of comparison between external and standard addition calibrations when studying possible matrix interferences.

\section{Comparison of Sample Preparation Procedures}

The comparison of six various preparation procedures of slim coffee samples prior to the determination of As and Se by HGICP-OES was performed by evaluating the precision and the accuracy of results achieved in addition to limits of detection (LODs) of As and Se. The precision was expressed as the relative standard deviation (RSD). LODs were determined as concentrations corresponding to three times the standard deviation $(3 \times \mathrm{SD})$ of ten executive measurements of respective procedural blanks ( $3 \sigma$ criterion). Spiking experiments and the determination of recoveries of added As and Se were used to check the accuracy. In these experiments, coffee $\mathrm{SC} 1$ was spiked with known amounts of As and Se species (0.25 and $0.50 \mu \mathrm{g} \mathrm{ml}^{-1}$ ) and analysed following the same sample preparation procedures and the pre-reductions. Finally, recoveries of As and Se for each sample preparation procedure followed by the HG-ICP-OES measurements were assessed. These results for $\mathrm{P} 1-\mathrm{P} 4$ procedures are listed in Table 3.

\section{Traditional Procedures}

As can be seen, results obtained using total wet digestion procedures $(\mathrm{P} 1, \mathrm{P} 2)$ demonstrate that both sample treatments are quite suitable for the coffee sample preparation. The precision of measurements and the accuracy obtained were almost the same. RSD values varied between $1.4-6.1 \%$ and 0.4-6.4 \% for hot-plate (P1) and MW-assisted (P2) wet digestions, respectively. Recovery values were, independently on the concentration and the speciation form of element, changed from $95.7 \%$ to $108.5 \%(\mathrm{P} 1)$ and from $98.1 \%$ to $107.1 \%$ (P2). Additionally, results for $\mathrm{As}(\mathrm{V})$ and $\mathrm{Se}(\mathrm{VI})$ prove the recommended pre-reduction step for converting As and $\mathrm{Se}$ into their lower oxidation states. The detectability of elements was also comparable. Differences between $\mathrm{As}(\mathrm{III})$ or $\mathrm{As}(\mathrm{V})$ and $\mathrm{Se}(\mathrm{IV})$ or $\mathrm{Se}(\mathrm{VI})$ were not marked; LOD values obtained using the hot-plate digestion procedure ( $\mathrm{P} 1)$ were only slightly higher (by 20-30\%).

\section{Alternative Procedures}

Among the procedures with no previous digestion (P3-P6), the solubilisation in TMAH (P4) was established to be justified, but only to the As determination. As can be seen in Table 3, quantitative recoveries were obtained for two considered As species (101.2-106.6\%), and RSDs (1.2-7.4\%) were practically the same as those achieved for wet digestion procedures (P1,P2). LODs of both As species resulted from the use of TMAH were however two times lower as compared to those assessed when using traditional procedures $(\mathrm{P} 1, \mathrm{P} 2)$. 
Table 3 The analytical characteristic of different coffee sample preparation procedures for the total As and Se determination by HG-ICP-OES

\begin{tabular}{|c|c|c|c|c|c|c|c|c|c|}
\hline \multicolumn{2}{|c|}{ Procedure } & \multicolumn{2}{|c|}{$\begin{array}{l}\text { Hot-plate heating } \\
\text { digestion }(\mathrm{P} 1)\end{array}$} & \multicolumn{2}{|c|}{$\begin{array}{l}\text { Microwave-assisted } \\
\text { digestion }(\mathrm{P} 2)\end{array}$} & \multicolumn{2}{|c|}{$\begin{array}{l}\text { Solubilisation in aqua } \\
\text { regia }(\mathrm{P} 3)\end{array}$} & \multicolumn{2}{|c|}{$\begin{array}{l}\text { Solubilisation in } \\
\text { TMAH (P4) }\end{array}$} \\
\hline Element & $\begin{array}{l}\text { Addition } \\
\text { Parameter }\end{array}$ & $0.25 \mu \mathrm{g} \mathrm{ml}^{-1}$ & $0.50 \mu \mathrm{g} \mathrm{ml}^{-1}$ & $0.25 \mu \mathrm{g} \mathrm{ml}^{-1}$ & $0.50 \mu \mathrm{g} \mathrm{ml}^{-1}$ & $0.25 \mu \mathrm{g} \mathrm{ml}^{-1}$ & $0.50 \mu \mathrm{g} \mathrm{ml}^{-1}$ & $0.25 \mu \mathrm{g} \mathrm{ml}^{-1}$ & $0.50 \mu \mathrm{g} \mathrm{ml}^{-1}$ \\
\hline \multicolumn{10}{|l|}{ As } \\
\hline \multirow[t]{3}{*}{$\mathrm{As}(\mathrm{III})$} & Recovery (\%) & 95.7 & 101.1 & 107.1 & 102.2 & 103.1 & 95.7 & 101.2 & 101.5 \\
\hline & RSD (\%) & 6.1 & 1.4 & 6.4 & 5.2 & 3.5 & 4.2 & 5.6 & 1.2 \\
\hline & $\operatorname{LOD}\left(\mathrm{ng} \mathrm{ml}^{-1}\right)$ & 4.3 & & 3.4 & & 0.97 & & 1.9 & \\
\hline \multirow[t]{3}{*}{$\mathrm{As}(\mathrm{V})$} & Recovery (\%) & 97.7 & 102.8 & 103.2 & 98.5 & 103.5 & 103.0 & 103.2 & 106.6 \\
\hline & RSD (\%) & 2.9 & 1.7 & 1.3 & 0.4 & 1.6 & 4.9 & 10.1 & 7.4 \\
\hline & $\operatorname{LOD}\left(\mathrm{ng} \mathrm{ml}^{-1}\right)$ & $4.3^{\mathrm{a}}$ & & $3.4^{\mathrm{a}}$ & & $0.96^{\mathrm{a}}$ & & $2.0^{\mathrm{a}}$ & \\
\hline \multicolumn{10}{|l|}{$\mathrm{Se}$} \\
\hline \multirow[t]{3}{*}{$\mathrm{Se}(\mathrm{IV})$} & Recovery (\%) & 106.1 & 99.2 & 102.5 & 99.4 & 100.6 & 104.1 & $\mathrm{ND}^{\mathrm{b}}$ & \\
\hline & $\operatorname{RSD}(\%)$ & 4.9 & 3.2 & 1.6 & 0.4 & 5.9 & 2.4 & & \\
\hline & $\operatorname{LOD}\left(\mathrm{ng} \mathrm{m}^{-1}\right)$ & 3.5 & & 2.6 & & 0.55 & & & \\
\hline \multirow[t]{3}{*}{$\mathrm{Se}(\mathrm{VI})$} & Recovery (\%) & 108.5 & 101.5 & 98.1 & 100.5 & 102.4 & 108.8 & $\mathrm{ND}^{\mathrm{b}}$ & \\
\hline & RSD (\%) & 4.1 & 3.0 & 4.6 & 1.1 & 7.1 & 2.1 & & \\
\hline & $\operatorname{LOD}\left(\mathrm{ng} \mathrm{ml}^{-1}\right)$ & $3.5^{\mathrm{a}}$ & & $2.4^{\mathrm{a}}$ & & $0.57^{\mathrm{a}}$ & & & \\
\hline
\end{tabular}

${ }^{\text {a }}$ As As(III) or Se(IV)

${ }^{\mathrm{b}}$ Not detected ( $0 \%$ as recovery); solid residue after pre-reduction of $\mathrm{Se}(\mathrm{VI})$ into $\mathrm{Se}(\mathrm{IV})$ with $6.0 \mathrm{~mol} 1^{-1} \mathrm{HCl}$

Unfortunately, this procedure was found ineffective for the Se determination (no recovery of Se observed). It was established that when the recommended pre-reduction step with $\mathrm{HCl}$ prior to the Se determination by HG-ICP-OES in sample solutions prepared was applied, a solid residue was formed in these conditions that particles possibly could retain the volatile element species and/or tend to its decay. Although the sample preparation procedure using TMAH for soluble coffee prior to its elemental analysis (including the Se content) was previously proposed in one work (Ribeiro et al. 2003), the conventional PN was applied there for elements' measurements by ICP-OES.

Simple coffee samples dissolutions in diluted $\mathrm{HNO}_{3}$ (P5) or water (P6) were unsuitable. It was evident mainly for Se, which could not be determined (no recovery) for the same reason as discussed previously when TMAH was used (P4) (formation of solid residue after pre-reduction step with $\mathrm{HCl}$ ). In case of As, the application of a diluted $\mathrm{HNO}_{3}$ solution (P5) led to much poorer recoveries $(9.5-12.8 \%)$ and the precision (6.1-11 \% as RSD), and up to two times higher detectability $\left(6.5 \mathrm{ng} \mathrm{ml}^{-1}\right)$ as compared to that achieved from the digestion procedures $(\mathrm{P} 1, \mathrm{P} 2)$. Using water for the sample dissolutions (P6), recoveries of As were high (80.3-90.1\%) but not quantitative. RSDs (4.6-8.4\%) were within the range obtained for wet digestions, while LODs $\left(2.3 \mathrm{ng} \mathrm{ml}^{-1}\right)$ were better than those achieved when traditional procedures $(\mathrm{P} 1, \mathrm{P} 2)$ were used. Additionally, it must be noticed that samples treated with diluted acid or water only required definitely the presence of Antifoam A in the reducing agent solution to avoid an extensive foam formation during the HG reaction, which affected the stability of ICP-OES.

The use of aqua regia (P3) was found to completely solubilise As and Se species, making them available for the HG reaction. Similar results for Se were obtained by Asfaw and Wibetoe (Asfaw and Wibetoe 2005). This treatment assures the complete recovery of both As forms that were changed from $100.6 \%$ to $108.8 \%$ (Se) and from $95.7 \%$ to $103.5 \%$ (As). RSD values obtained in these conditions, i.e., 2.1-7.1\% (Se) and 1.6-4.9\% (As), confirm the good precision of measurements. Satisfactorily, LODs of As and Se evaluated for this sample treatment were also the lowest. Accordingly, they were from four (As) to six (Se) times lower than those achieved for the MW-assisted wet digestion (P2) as well as 12 orders on magnitude lower in comparison to those estimated when applying PN to measure As and Se by ICP-OES (As: $88 \mathrm{ng} \mathrm{ml}^{-1}$; Se: $59 \mathrm{ng} \mathrm{ml}^{-1}$ ). Thus, it seems that the solubilisation in aqua regia is adequate for the determination of traces of As and Se in samples of soluble coffee. Sample solutions obtained during the proceeding with aqua regia were orange-yellow slurries, suggesting a partial decomposition of the organic matter of coffee samples. No precipitation was found when the pre-reduction step prior the total As and Se determination by HG was carried out. In contrast, for the remaining procedures $(\mathrm{P} 4, \mathrm{P} 5, \mathrm{P} 6)$ resulting samples solutions were brown, suggesting the simple coffee dissolution instead of the partial decomposition, which can explain the later difficulties in Se measurements. 
To conclude, the solubilisation in aqua regia offers a simple and reliable alternative way to instant coffee analysis for the total content of As and Se without the need for complete digestion of sample matrix. Consequently, it was chosen for further studies.

\section{Optimization and Verification of Alternative Procedure}

An optimal $\mathrm{S} / \mathrm{L}$ ratio (solid-to-liquid, $\mathrm{m} / \mathrm{v}$ ) for the sample preparation with aqua regia ( $\mathrm{P} 3)$ was evaluated, assuring the complete recovery of As and Se forms. The following sample masses and final sample solutions (including $2 \mathrm{ml}$ of aqua regia added) were tested: $0.5 / 10,0.5 / 25,1 / 10$ and $1 / 25(\mathrm{~g} / \mathrm{ml})$. Resulting sample slurries were sonicated for $15 \mathrm{~min}$, made up to the required volume with water and centrifuged before the analysis. Concentrations of resulting sample solutions were $5 \%, 2 \%, 10 \%$ and $4 \%(\mathrm{~m} / \mathrm{v})$. The results were evaluated as arsenic and selenium recoveries using the standard addition method. It was observed that releasing of As and Se into solutions depended on the S/L ratio and increased with the dilution. The best results, i.e., quantitative recoveries, were found for a sample solution concentration of $2 \%$. A lowering in the recovery of As and Se for the higher concentration (4 $10 \%$ ) was suspected, because obtained sample solutions were from non-clear (2-4\%) to even muddy (10\%) and required an additional filtration before the analysis. Such an effect was not observed for the $2 \%$ solution.

In addition, spiking experiments on developed sample preparation and pre-reduction procedures were carried out and different concentrations of $\mathrm{Se}(\mathrm{IV}, \mathrm{VI})$ and $\mathrm{As}(\mathrm{III}, \mathrm{V})$ were added $\left(0.1-0.5 \mu \mathrm{g} \mathrm{ml}^{-1}\right)$ as a single one or both of the As or Se species considered. Recovery values obtained were from $97.8 \%$ to $106.2 \%$ (Se) and from $98.1 \%$ to $106.5 \%$ (As), evidencing the absence of losses of As and Se or the contamination during all steps of the analysis.

Another experiment, made to verify the reliability of the proposed methodology (P3), was based on the comparison of concentrations of As and Se determined in instant coffee SC1 using this procedure with those determined in sample solutions resulted from the complete acidic digestion of respective samples $(\mathrm{P} 1, \mathrm{P} 2)$. Preliminary investigations showed that coffee chosen for the optimization (SC1) has Se below the LOD. Therefore, in the case of Se, the NIST SRM 1549 with a certified concentration of Se was analysed. As shown in Table 4, results obtained with the partial sample decomposition (P3) correspond well with those obtained after the execution of total wet digestion procedures (in case of As) and with the certified value, i.e., $102.4 \%$ as recovery (in case of $\mathrm{Se})$. Moreover, the solubilisation in aqua regia was the only procedure that was adequate for the Se determination in the NIST SRM 1549. Additionally, the comparison of results achieved using for the calibration the method of standard additions and external standards (see Table 4) indicates that
Table 4 The comparison of As and Se contents (mean $\pm \mathrm{SD}, n=3$ ) in the slim coffee SC1 and the NIST SRM 1549 obtained after the solubilisation in aqua regia and the wet digestion of their samples and using the external standard calibration

\begin{tabular}{lll}
\hline Procedure & \multicolumn{2}{c}{ Concentration $\left(\mu \mathrm{g} \mathrm{g}^{-1}\right)$} \\
\cline { 2 - 3 } & $\begin{array}{l}\text { As } \\
\text { soluble slim coffee (SC1) }\end{array}$ & $\begin{array}{l}\text { Se } \\
\text { SRM } 1549^{\mathrm{a}} \text { (non-fat milk) }\end{array}$ \\
\hline P1 & $0.232 \pm 0.013$ & $\mathrm{ND}^{\mathrm{c}}$ \\
& $0.221 \pm 0.006^{\mathrm{b}}$ & \\
P2 & $0.197 \pm 0.013$ & $\mathrm{ND}^{\mathrm{c}}$ \\
& $0.232 \pm 0.010^{\mathrm{b}}$ & \\
P3 & $0.242 \pm 0.008$ & $0.113 \pm 0.008$ \\
& $0.248 \pm 0.021^{\mathrm{b}}$ & \\
\hline
\end{tabular}

P1 hot-plate wet digestion, P2 microwave-assisted wet digestion, P3 solubilisation in aqua regia

${ }^{\mathrm{a}}$ Certified value $0.11 \pm 0.01 \mu \mathrm{g} \mathrm{g}{ }^{-1}$

${ }^{\mathrm{b}}$ Using standard addition calibration

${ }^{\mathrm{c}}$ Not detected

no matrix effects were present when using the proposed methodology.

\section{Application}

The proposed procedure (the solubilisation in aqua regia, $\mathrm{P} 3$ ) was used to determine total As and Se concentrations in various slim coffees (SC1-SC6) and in one common instant coffee $(\mathrm{C})$, for comparison. Results are presented in Table 5.

As can be seen, the precision typically varied between $6.0 \%$ and $9.0 \%$ (as RSD). Much higher RSD values (11-13\%) were obtained when extremely low concentrations of As and Se were present in analysed coffees. It was established that concentrations of As ranged from undetectable to $0.247 \mu \mathrm{g} \mathrm{g}^{-1}$. In the case of $\mathrm{Se}$, it was from undetectable to $0.137 \mu \mathrm{g} \mathrm{g}^{-1}$. In two samples, i.e., SC3 and SC6, both As and Se contents were below their respective LOD values. Contents of As and Se found in $100 \%$ instant coffee $(\mathrm{C})$ were close and up to two

Table 5 Total Se and As concentrations in analysed instant coffees using the developed methodology

\begin{tabular}{|c|c|c|c|}
\hline \multirow{5}{*}{$\begin{array}{l}\text { Table } 5 \text { Total Se and As } \\
\text { concentrations in } \\
\text { analysed instant coffees } \\
\text { using the developed } \\
\text { methodology }\end{array}$} & \multirow{3}{*}{$\begin{array}{l}\text { Samples } \\
\text { SC1 }\end{array}$} & \multicolumn{2}{|c|}{ Concentration $^{\mathrm{a}}\left(\mu \mathrm{g} \mathrm{g}^{-1}\right)$} \\
\hline & & $\mathrm{Se}$ & As \\
\hline & & $<\mathrm{LOD}^{\mathrm{b}}$ & $0.247(8.5)$ \\
\hline & $\mathrm{SC} 2$ & $0.089(13)$ & $<\mathrm{LOD}^{\mathrm{b}}$ \\
\hline & $\mathrm{SC} 3$ & $<\mathrm{LOD}^{\mathrm{b}}$ & $<\mathrm{LOD}^{\mathrm{b}}$ \\
\hline \multirow{4}{*}{$\begin{array}{l}{ }^{\text {a }} \text { Average values }(n=3) \\
\text { with relative standard of } \\
\text { deviation (RSD) in } \\
\text { brackets }\end{array}$} & $\mathrm{SC} 4$ & $0.137(9.0)$ & $0.114(11)$ \\
\hline & SC5 & $<\mathrm{LOD}^{\mathrm{b}}$ & $0.143(7.6)$ \\
\hline & SC6 & $<\mathrm{LOD}^{\mathrm{b}}$ & $<\mathrm{LOD}^{\mathrm{b}}$ \\
\hline & $\mathrm{C}$ & $0.240(6.6)$ & $0.282(6.0)$ \\
\hline
\end{tabular}


times higher, respectively, than average values determined in analysed slim coffee products. Ought to the lack of works concerning the analysis of slim instant coffees for total As and $\mathrm{Se}$, concentrations of these elements were compared to those reported for typical instant coffees. Our results were well suited within concentrations ranges given by others authors, As $<0.200 \mu \mathrm{g} \mathrm{g}^{-1}$ (Vega-Carrillo et al. 2002; Jose dos Santos and de Oliveira 2001) and $\mathrm{Se}<0.300 \mu \mathrm{g} \mathrm{g}^{-1}$ (Vega-Carrillo et al. 2002; Jose dos Santos and de Oliveira 2001; Ribeiro et al. 2003; Asfaw and Wibetoe 2005).

\section{Conclusions}

The efficiency of As and Se HG was found to be strongly dependent on the sample preparation procedure and reducing conditions. The degree of the sample decomposition was critical and affected the $\mathrm{H}_{2} \mathrm{Se}$ formation. The developed and optimized analytical methodology based on the partial decomposition of samples using their solubilisation in aqua regia and ultrasonication of sample slurries formed at room temperature, followed by the pre-reduction of element species with $\mathrm{KI}$-ascorbic acid (for total As) and boiling with $\mathrm{HCl}$ (for total Se) and finally the detection of both elements by HG-ICP-OES demonstrates the appropriate reproducibility, precision, accuracy, and sensitivity for dependable determinations of traces of As and Se in soluble slim coffee products. The partial decomposition was found to be especially essential in the case of Se, which could be completely lost during the recommended prereduction step of $\mathrm{Se}(\mathrm{VI})$ with $\mathrm{HCl}$ prior to the $\mathrm{HG}$ reaction if other sample preparation procedures were used, e.g., the solubilisation in TMAH, the dissolution in diluted $\mathrm{HNO}_{3}$ or water only. In the case of As, the treatment with aqua regia followed by the pre-reduction of $\mathrm{As}(\mathrm{V})$ with $\mathrm{KI}$-ascorbic acid enabled to increase the signal of As by nearly $50 \%$ as compared to the result of an aqueous arsenic standard acidified only with $\mathrm{HCl}$ (without any additives).
The proposed procedure is safe, reduces the sample handling, minimizes the time and reagent consumption as well eliminates losses of As and Se or the contamination of samples. Thus, it can be a vital alternative to traditional sample treatment approaches based on the wet digestion with concentrated oxidative reagents.

The analysis of various soluble coffee products indicates that some of them contain traces of As and Se, i.e., below $0.3 \mu \mathrm{g} \mathrm{g}^{-1}$.

Acknowledgments The work was financed by a statutory activity subsidy from the Polish Ministry of Science and Higher Education for the Faculty of Chemistry of Wrocław University of Technology.

Conflict of interest Maja Welna declares that she has no conflict of interest. Anna Szymczycha-Madeja declares that she has no conflict of interest. Pawel Pohl declares that he has no conflict of interest. This article does not contain any studies with human or animal subjects.

Open Access This article is distributed under the terms of the Creative Commons Attribution License which permits any use, distribution, and reproduction in any medium, provided the original author(s) and the source are credited.

\section{References}

Pohl P, Stelmach E, Welna M, Szymczycha-Madeja A (2013) Food Anal Meth 6:598

Vega-Carrillo HR, Iskander FY, Manzanares-Acuna E (2002) J Radioanal Nucl Chem 252:75

Oliveira M, Casal S, Morais S, Alves C, Dias F, Ramos S, Mendes E, Delerue-Matos C, Oliveira MBPP (2012) Food Chem 130:702

Pohl P (2004) Trends Anal Chem 23:1

Jose dos Santos E, de Oliveira E (2001) Braz Arch Biol Technol 44:233

Ribeiro AS, Moretto AL, Arruda MAZ, Cadore S (2003) Microchim Acta 141:149

Asfaw A, Wibetoe G (2005) Anal Bioanal Chem 382:173

Anthemidis AN, Pliatsika VG (2005) J Anal At Spectrom 20:1280

Magalhaes CEC, Lima EC, Krug FJ, Arruda MAZ (1999) Microchim Acta 132:95

Welna M, Lasowska J, Zyrnicki W (2011) J Braz Chem Soc 22:1164

Uggerud H, Lund W (1995) J Anal At Spectrom 10:405 